\title{
Report from the Second European Stroke Summer School, Heidelberg, Germany
}

\author{
Christiane E. Ehrenfeld
}

on behalf of the participants

The Second European Stroke Summer School was held in Oberflockenbach near Heidelberg/Mannheim, Germany, from the 19th to the 26th of July 1998. Thirty participants from twelve different countries not only from Europe but also from Brazil and South Africa attended. Prof. Kjell Asplund was the initiator of the idea of a summer school on stroke and organizer of the first meeting held in summer 1997 in Umeå, Sweden. He intended to bring together young physicians from various countries interested in cerebrovascular diseases for further training in state-of-the-art stroke research, diagnostics and treatment with lectures from international experts.

This year, the summer school was organized by Prof. Werner Hacke from Heidelberg, Germany, and Prof. Michael Hennerici from Mannheim, Germany.

The main topic on the first day was acute stroke treatment, with lectures given by Prof. Hennerici (General Treatment), Prof. Hacke (Thrombolysis), Prof. Markku Kaste, Helsinki/Finland (Neuroprotectants) and Dr. Stefan Schwab, Heidelberg (Ischemic Brain Edema). Prof. Hennerici stressed the importance of blood pressure, body temperature and blood glucose in acute stroke patients. Prof. Hacke summarized the trials dealing with thrombolysis and summarized the results of ECASS II, which will be presented in September this year. Prof. Kaste gave an overview of recent clinical trials on neuroprotectants. He suggested trials with combined therapy, either neuroprotectants and rTPA or different neuroprotective drugs.

The second day's main topics were epidemiology and clinical trials with lectures by Prof. Heiko Becher, Mainz, Germany (A Primer on Epidemiology), Prof. Stefan Willich, Berlin, Germany (Epidemiology of Vascular Diseases), Dr. Armin Grau, Heidelberg, Germany (Recently Identified Risk Factors for Stroke), Dr. Erich Bluhmki, Ingelheim, Germany (Modern Approaches to Outcome in Stroke Trials), Dr. Jürgen Windeler, Heidelberg, Germany (Clinical Trial Methodology), Prof. Kjell Asplund, Umeå, Sweden (Evidence-Based Medicine: Secondary Prevention of Stroke) and Dr. Alexander Boddy, Malvern, USA (Applied Trial Statistics, Lessons from CAPRIE).
Dr. Grau named recently identified risk factors for stroke, like hyperhomocysteinemia, fibrinogen or other markers of inflammation (e.g. CRP, leukocytes) and stressed the relationship between infectious airway diseases and stroke.

The main topic, diagnostics, on the third day included lectures by Prof. Rüdiger von Kummer, Dresden, Germany (CT Scanning), Prof. Andreas Schwartz and Dr. Achim Gass both from Mannheim, Germany (Diffusion and Perfusion MRI), Dr. Stephan Meairs, Mannheim, Germany (Recent Advances in Neurosonology) and Dr. Helmut Kücherer, Heidelberg, Germany (Cardiac Ultrasound in Acute Stroke). Prof. von Kummer and Prof. Schwartz talked about early CT and MRI signs of ischemic infarction and the diagnostic value of both imaging techniques. Dr. Meairs gave an overview of recent advances in neurosonology and expected that these diagnostic methods would gain increasing clinical value.

The main topics on the fourth day were molecular biology and basic science with lectures given by Prof. Wolfgang Kuschinsky, Heidelberg, Germany (Regulation of the Cerebral Blood Flow), Dr. Ulrich Dirnagel, Berlin, Germany (Spreading Depression and Penumbra), Dr. Markus Schwanninger, Heidelberg, Germany (Excitotoxicity), Dr. Matthias Spranger, Heidelberg, Germany (The Two Faces of NO) and Nobel Laureate Prof. Bert Sakmann, Heidelberg, Germany (Cellular Electrophysiology). These lectures clarified the pathophysiological background of cerebral blood flow and the mechanisms of ischemia.

Small group visits to Stroke Units in Mannheim and Heidelberg as well as to the Neurological Critical Care Unit in Heidelberg and the Neuroimaging laboratories at both sites offered practical insights. The outstanding opportunities for basic science in Heidelberg were evoked by Prof. Konrad Bayreuther [Prof. Klaus Nave (Center of Molecular Biology Heidelberg], Prof. Bert Sakmann (Max Planck Institute of Medical Research) as well as Prof. Wolfgang Kuschinsky (Dep. of Neurophysiology, Heidelberg).

\section{KARGER}

(c) 1999 S. Karger AG, Basel

Fax +41 613061234

E-Mail karger@karger.ch www. karger.com
Accessible online at: http://BioMedNet.com/karger 
The well-balanced program covered a broad spectrum of issues. It did not only provide state-of-the-art knowledge but also offered the opportunity for in-depth discussions.

One day was reserved for the presentation of the participants' own work. This encompassed varied subjects, such as first experiences with a stroke unit in Brazil, case series on Cadasil and local thrombolysis in sinus venous thrombosis, dynamic cerebral autoregulation and NO in man. The organizers provided an active and stimulating entertainment program including visits to the famous castle of Heidelberg, the historical cathedral of Speyer and the vineyards of the Palatinate.

Summer schools provide a unique opportunity for young researchers to meet and exchange ideas in a creative environment. It is hoped to be a long-running fixture of the academic calendar.

Dr. Christiane E. Ehrenfeld, Neurologische Universitätsklinik, Hufelandstr. 55, D-45122 Essen (Germany)

\section{European Stroke Council}

\section{Minutes of General Assembly \\ May 29, 1998, Sidlaw Room, EICC, Edinburgh}

\section{(1) Report from the Chairman}

The chairman reported from the Executive Committee that:

- the management (conference) committee will be effective as from the 1999 European Stroke Conference;

- a reduced registration fee at the European Stroke Conferences for members of the ESC had been proposed, to become effective in 2000;

- Cerebrovascular Diseases, the official journal of the ESC, was recently included in the Index Medicus, and

- teaching courses will be organized in conjunction with forthcoming European Stroke Conferences, to be effective at the 1999 meeting.

The logotype of the ESC, prepared by Jean-Marc Orgogozo, was adopted by the General Assembly.

\section{(2) Report from the Secretary}

The secretary reported on the current membership status of the ESC.

\section{(3) European Stroke Summer Schools}

The 2nd European Stroke Summer School will be organized by Werner Hacke in Heidelberg in August 1998. Charles Warlow announced that he accepted the proposal from the Executive Committee to organize the course next year in Edinburgh.

(4) Reports on the Progress of EUSI and on the Implementation of the Helsingborg Declaration

Markku Kaste reported on the progress of the EUSI. A slide kit on 'acute stroke' and a booklet on 'stroke prevention' are currently being prepared. The EUSI is financially supporting the European Stroke Summer School.

Bo Norrving reported that the steering committee for the Implementation of the Helsingborg Declaration had met twice during the last year. A plan of action for the implementation has been established, including preparation of a 'minimum data set' for assessment of quality of stroke care and preparation of guidelines on 'stroke units' and 'acute care of stroke'. Funding for the implementation process had not yet been achieved.

\section{(5) Election of New Members to the Executive Committee}

The General Assembly approved the proposal from the executive committee on electing 4 new members this year, and that 2 of the current members elected in 1994 should remain in office for 2 more years.

By a closed voting, the General Assembly elected Julien Bogousslavsky, Antoni Dávalos, Kennedy Lees, and Didier Leys as new members of the Executive Committee (duration in office for 4 years).

\section{(6) Other Business}

Markku Kaste reported that a 'World Stroke Day' was to be announced next year, and that a meeting in Berlin aiming to establish an international patient organization for stroke was planned later this year.

Bo Norrving, Secretary of the ESC

Jean-Marc Orgogozo, Chairman of the ESC

\section{Minutes of Executive Committee Meeting}

May 30, 1998, Gladsmuir Room, EICC, Edinburgh

The following members were present: Julien Bogousslavsky, Bo Norrving, Gian Luigi Lenzi, Antoni Dávalos, José Ferro, Werner Hacke, Markku Kaste, Didier Leys. Regrets: Kennedy Lees.

\section{(1) Election of Chairman}

The committee elected Julien Bogousslavsky as chairman for the next 2 years, succeeding Jean-Marc Orgogozo.

\section{(2) Election of Treasurer}

The committee elected Gian Luigi Lenzi as treasurer for the next 4 years. 
(3) ESC Newsletters in Cerebrovascular Diseases

Julien Bogousslavsky reported that S. Karger AG has granted permission for the Executive Committee to publish information (Newsletters of 6 printed pages per year) on the ESC in Cerebrovascular Diseases. This privilege has not been fully utilized previously. It was decided that announcements and reports on the European Summer Schools, a list of the members of the Executive Committee, and other relevant information should from now on be published regularly in Cerebrovascular Diseases.

\section{(4) Preparation of Edifice of Membership for New Members of the ESC}

The secretary was given the task to prepare an edifice of membership of the ESC to be given to new members. The edifice should include the new logotype of the ESC and should be signed by the chairman and the secretary.

\section{(5) Organization of Poster Discussions at European Stroke}

\section{Conferences}

Werner Hacke was given the task to promote the organization of poster session discussions at forthcoming European Stroke Conferences, similar to the format introduced by Michael Hennerici at this year's conference.

\section{(6) Subcommittees of the ESC}

The subcommittees of the ESC were reviewed. Three subcommittees (education, EUSI, and the Implementation of the Helsingborg Declaration) are now existing, whereas the subcommittees on ethics and standards are currently not active.

\section{(7) Next Meeting of the Executive Committee}

It was proposed that the Executive Committee should meet next time during the Joint Conference on Stroke and Cerebral Circulation in Nashville, Tenn., February 1999, provided that a majority of the members would attend. At the European Stroke Conference in Venice 1999, a joint meeting with the Executive Committee and the program committee should be arranged, as proposed by the Executive Committee in 1997.

Bo Norrving, Secretary of the ESC

Julien Bogousslavsky, Chairman of the ESC 